\title{
Total hip arthroplasty in the elderly: impact on functional performance
}

\author{
Artroplastia total de quadril em idosos: impacto na funcionalidade
}

Rita C. Guedes', João M. D. Dias², Rosângela C. Dias², Viviane S. Borges³, Lygia P. Lustosa', Nayza M. B. Rosa³

\section{Abstract}

Objectives: To compare gait and functional performance parameters in elderly subjects who had or had not total hip arthroplasty (THA). Methods: Our sample comprised 23 elderly subjects ( $72 \pm 6.5$ years of age) with a mean of $2.6 \pm 1.3$ years following THA, named the arthroplasty group (AG) and 23 asymptomatic elderly subjects ( $70.1 \pm 5.9$ years of age), named the control group (CG). Case and control subjects were paired by gender, age, body mass index and level of physical activity. The GAITRite ${ }^{\circledR}$ system was used to analyze various gait parameters in four situations: usual speed (US), fast speed (FS), slow speed (SS) and dual task (DT); the Dynamic Gait Index (DGI) and Timed Up and Go test (TUG) methods were used to evaluate functional capacity. The statistical analyses were carried out using the Shapiro-Wilk test, Student's-t-tests for independent samples, chi-square tests, ANOVA for repeated measurements and paired Student's-t-tests. Results: The AG had the worst results for gait speed $(A G=1.18 \pm 0.13$ and $C G=1.39 \pm 0.09 ; p=0.012)$, symmetry index (SI) of step length ( $A G=3.60 \pm 1.01$ and $C G=1.12 \pm 0.59 ; p=0.000)$, SI of step time ( $A G=-2.65 \pm 0.92$ and $C G=0.99 \pm 0.74 ; p=0.000)$, $S I$ of stance phase $(A G=-2.55$ and $C G=-1.04 \pm 0.50 ; p=0.005)$, SI of single support phase $(A G=-2.17 \pm 0.78$ and $C G=1.21 \pm 0.51 ; p=0.003)$, DGI $(A G=20.04 \pm 1.91$ and $C G=21.69 \pm 1.45 ; p=0.001)$ and $T U G(A G=14.67 \pm 1.94$ and $C G=10.08 \pm 1.49 ; p=0.001)$. Conclusion: Elderly subjects with a history of THA had changes in gait parameters and lower performance in TUG test even 2.6 $\pm 1,3$ years after surgery, which suggests functional impairment.

Keywords: aged; osteoarthritis; hip; arthroplasty; gait.

\section{Resumo}

Objetivos: Comparar os parâmetros da marcha e o desempenho funcional de idosos com e sem artroplastia total de quadril (ATQ). Métodos: Foram selecionados 23 idosos ( $72 \pm 6,5$ anos) após média de 2,6 $\pm 1,3$ anos de ATQ e 23 idosos assintomáticos (70,1 $\pm 5,9$ anos), pareados por gênero, idade, índice de massa corpórea (IMC) e nível de atividade física. Utilizou-se o sistema GAITRite ${ }^{\circledR}$ em quatro situações distintas: velocidades habitual (VH), rápida (VR), lenta (VL) e tarefa dupla (TD). A capacidade funcional foi avaliada pelo Dynamic Gait Index (DGI) e Timed Up and Go (TUG). Na análise estatística, utilizaram-se os testes Shapiro-Wilk, t-Student para amostras independentes, Qui-quadrado, ANOVA com medidas repetidas e t-Student pareado. Resultados: O grupo artroplastia (GA) apresentou piores resultados estatisticamente significantes no que se refere à velocidade de marcha $(\mathrm{VM})(\mathrm{GA}=1,18 \pm 0,13 \mathrm{e}$ $G C=1,39 \pm 0,09 ; p=0,012)$, índice de simetria (IS) do comprimento do passo ( $G A=3,60 \pm 1,01$ e $G C=1,12 \pm 0,59 ; p=0,000)$, IS do tempo do passo ( $G A=-2,65 \pm 0,92$ e $G C=0,99 \pm 0,74 ; p=0,000)$, IS da duração da fase de apoio $(G A=-2,55$ e $G C=-1,04 \pm 0,50 ; p=0,005)$, IS da duração da subfase de apoio único ( $G A=-2,17 \pm 0,78$ e $G C=1,21 \pm 0,51 ; p=0,003)$, $D G l(G A=20,04 \pm 1,91$ e $G C=21,69 \pm 1,45 ; p=0,001)$ e TUG ( $G A=14,67 \pm 1,94$ e $G C=10,08 \pm 1,49 ; p=0,001)$. Conclusão: Idosos com ATQ apresentaram alterações nos parâmetros da marcha, mesmo após 2,6 $\pm 1,3$ anos de cirurgia, e pior desempenho no teste TUG, indicando comprometimento funcional.

Palavras-chave: idoso; osteoartrite; quadril; artroplastia; marcha.

Received: 30/03/2010 - Revised: 10/08/2010 - Accepted: 03/09/2010 


\section{Introduction $: \therefore$.}

Total primary hip arthroplasty (THA) is a surgical procedure that is widely used for the treatment of hip osteoarthritis ${ }^{1}$. There are no statistics available concerning the number of THAs currently being performed in Brazil, but it is estimated that in 2026, the number of THAs performed in Brazil annually will be about 572,000, at a total cost of 15 billion US dollars². The most common indication for THA is the presence of severe pain ${ }^{3}$ accompanied by functional limitation ${ }^{14}$. THA is one of the most successful orthopedic surgeries, with satisfactory results such as pain relief and physical functional improvement, which allows the subject to return to his/her activities of daily living $(\mathrm{ADLs})^{5}$.

Gait assessment is an important measure of postoperative outcomes after THA because gait is an important indicator of functional recovery ${ }^{5,6}$. An individual's independence is directly related to his/her ability to adjust gait according to his/her daily demands in varying environments such as walking at different velocities and on different surfaces, which are often associated with tasks that require intensive attention ${ }^{6}$.

Gait modifications are expressed in temporal and spatial measures, such as gait speed (GS) and step length, and on the duration of the balance and stance phases of the gait ${ }^{6,7}$. However, there is no consensus in the literature about the continued improvement in gait after THA. Some studies show that gait worsens over time ${ }^{5,8}$, while others show improvement in these parameters after arthroplasty ${ }^{6,9}$.

Kyriasis and Rigas ${ }^{8}$ compared the gait parameters of subjects in four distinct groups walking at usual and fast speeds (US and FS): before THA, one year post-THA, 10 years postTHA and in subjects who had not undergone THA. The authors observed that the post-THA participants improved their gait parameters over time, but their gait always remained worse than that of subjects in the control group (CG). Bennett et al. ${ }^{5}$ performed three-dimensional gait analysis of older adults ten years after THA, comparing them with asymptomatic older adults. The variables analyzed were GS, cadence, step length and duration of the stance phase of gait, and they observed that the subjects showed significant impairment in these parameters, suggesting that muscle atrophy and residual stiffness could influence gait, even several years after surgery.

In contrast, Van Den Akker-Scheek et al. ${ }^{6}$ evaluated the gait of a group of subjects before, six weeks after and six months after THA and observed an improvement in GS, length and duration of the step after six months. Similarly, Rasch, Dalén and Berg 9 analyzed the gait of 20 older subjects before, six months after and two years after THA, and prior to surgery, they identified a shorter phase of single support in the limb with hip osteoarthritis compared to the contra lateral limb. Six months after surgery, subjects had resumed gait patterns that were close to normal.

In this context, due to the lack of consensus regarding the recovery of a normal gait pattern after THA, the goals of the present study were to compare temporal and spatial gait parameters of older adults with and without THA in casual gait situations, with increases and decreases in velocity and with the gait associated with a cognitive task and also to compare the functional performance of elderly individuals who had and had not undergone THA.

\section{Methods : :}

\section{Sample}

After taking into account the sampling calculations based on gait parameters from previous studies that used the gait analyzing system GAITRite ${ }^{\circledR 10-12}$, we used a convenience sample to recruit 46 community-dwelling elderly subjects of both genders. The arthroplasty group (AG) comprised 23 subjects who had undergone THA with cemented prosthesis and posterolateral approach. The control group (CG) comprised 23 subjects with no history of THA.

Individuals were excluded from this trial if they met one of the following criteria: history of other orthopedic surgical procedures in the lower limbs (LLs) or vertebral spine; complaint of pain in the LLs not related to THA; physical therapy in the three months before data collection; differences in LL length that were not corrected and were above 1,5 cm; severe balance impairment, neurological, cardiovascular, or musculoskeletal decompensate diseases that prevented the execution of the tests; and suggestive cognitive impairment, indicated by the Mini-Mental State Exam ${ }^{13}$. The older adults in the CG met the same selection criteria, except they had not undergone THA. To make the two groups comparable, we paired subjects by gender, age, body mass index (BMI) and level of physical activity. This study was approved by the Ethics Committee of Research from the Universidade Federal de Minas Gerais (UFMG), Belo Horizonte, MG, Brazil, under the protocol n ${ }^{\circ}$ ETIC 586/08, and all the participants signed a voluntary informed consent statement.

\section{Instruments}

Gait parameters were analyzed using the GAITRite ${ }^{\circledast}$ (MAP/CIR INK, Haverton, PA, USA) system, which consists of an electronic rubberized rug that registers plantar pressures, allowing the calculation of temporal and spatial gait data ${ }^{10}$. This 
rug is $90 \mathrm{~cm}$ wide by $566 \mathrm{~cm}$ long and $0.6 \mathrm{~cm}$ thick, with 18.824 built-in pressure sensors. The system also has data analysis and documentation software for nine temporal and six spatial parameters of gait. A large number of studies have documented the validity and reliability of its measures in comparison with other techniques, including studies with older adults ${ }^{10-12}$.

Functional performance was evaluated using the Dynamic Gait Index (DGI ${ }^{14}$, which is composed of eight functional tasks involving gait with diverse contexts of sensitivity, including walking on a flat surface, changes in GS, head movements, stepping over and around exercises, rotating on the body axis, climbing and descending stairs. The scores range from 0 to 24 points and higher scores indicate better functional performance. This instrument was developed by Shumway-Cook and Woolacott ${ }^{15}$ and was further adapted to a Brazilian population by De Castro, Perracini and Ganança ${ }^{14}$. The DGI is capable of identifying subjects with balance impairments, and offers useful measures to identify gait changes ${ }^{16}$.

For functional assessment, we also used the Timed Up and Go (TUG) test, which is a measure of mobility with good levels of inter- and intra-rater reliability (CCI 0.99) $)^{17,18}$. Because this test evaluates a series of maneuvers used in daily routines, it has good correlation with balance measures, GS and functional abilities. TUG allows for the assessment of sitting balance, the change from sitting to standing positions, and stability during the gait and on gait course ${ }^{19}$.

The Physical Activity Trends (PAT) questionnaire is used to classify a subject's level of physical activity based on the type of activity, its frequency and duration. The subject's activity level is categorized as "inactive", "insufficient", "moderate" and "vigorous" ${ }^{20}$. The PAT was filled out by the researcher.

\section{Procedures}

Subjects in the AG were recruited by telephone from a cohort of patients who had undergone THA in a hospital of the public health system, and the CG was selected in university extension projects for asymptomatic elderly and through spontaneous request for participation made after divulgation of the study purpose.

We used a questionnaire to collect personal and clinical data. The questionnaire was created for this research and aimed to characterize the participants and categorize their level of physical activity using the PAT $^{20}$. After completing the questionnaire, subjects were evaluated using the functional tests DGI and TUG, and the analysis of gait was performed using the GAITRite ${ }^{\circledR}$ system. The assessment was performed in a single day, with an interval of at least five minutes between the measures to minimize possible effects of muscular fatigue. The order of the performance of the tests was random, and all of the tests were done by the same evaluator.

As determined in a pilot study, the participants were oriented to walk on the GAITRite ${ }^{\circledR}$ in four distinct test situations $^{6}$, completing six turns in each situation: 1) walking at their usual speed (US); 2) walking as fast as possible without running (FS); 3) walking as slow as possible (SS) and 4) walking as usual while making mathematical calculations, a situation named dual task (DT) ${ }^{6,21,22}$. To avoid the influence of acceleration and deceleration, subjects initiated gait from a point located two meters before the rug and stopped at a point located two meters after the rug. Both points were marked with a cone.

\section{Data reduction}

Spatial and temporal gait parameters were obtained through specific software using the GAITRite ${ }^{\circledR}$ system through which we also determined the normalized speed by dividing the speed by the mean length of the $\mathrm{LL}^{23}$. Data relative to the normalized speed, cadence, step duration, step length and the duration of stance and single support were registered for each subject. The mean of each of these parameters was used for the statistical analysis.

To process the gait data, the symmetry index $(\mathrm{SI})^{24}$ was calculated for the step length, step duration and duration of stance and single support phases of gait. The SI consists of a measure that compares any parameter between the operated limb (OPL) and the non-operated limb (NOL) through the following equation, in which $\mathrm{X}$ is the mean of the parameter:

$$
\mathrm{SI}=\frac{X O P L-X N O L}{0.5(X O P L+X N O L)} \times 100 \%
$$

Values of SI equal to zero indicate a perfect symmetry between the limbs. Negative values indicate that OPL parameters are shorter than those from the NOL, and positive values indicate longer parameters for the OPL. For the group of older adults without THA (i.e., CG), OPL was referred to as the nondominant LL and NOL was referred to as the dominant $\mathrm{LL}^{24}$.

\section{Statistical analysis}

The analysis of data normality was performed through the Shapiro-Wilk test. For the comparison between groups, Student's-t-tests were used for independent samples in the case of continuous data, and the chi-square test was used for categorical data. For the comparisons between the LL of the subjects with THA, the paired Student's-t-test was used, and for the comparisons between the four test situations of each 
group, ANOVA was used for repeated measures with multiple comparisons done using Tukey's test. The level of significance was set at $\alpha=0,05$. Data were analyzed using SPSS, version 17.0, in a Windows environment.

\section{Results $: \therefore$.}

Participants included 46 older adults, of whom 23 had undergone THA (AG) and 23 had not (CG). In terms of clinical and demographic characteristics, there were no significant differences between groups in terms of age, gender, BMI or level of physical activity (Tables 1 and 2). When comparing the OPL and the NOL from AG subjects, we observed a significant difference in the four distinct test situations, with longer step length, shorter step duration, shorter duration of the stance and single support phases in the OPL. The results are presented in Table 3.

In the comparison between $\mathrm{AG}$ and $\mathrm{CG}$ subjects, we observed a lower GS in AG subjects, in addition to a greater SI of the step length, step duration and duration of the stance phase and the single support phase. The AG subjects presented a longer mean time on TUG and lower mean scores on DGI (Table 4). We also observed statistically significant differences between the diverse test situations within each group and between both groups, except when comparing the situation SS with DT (Table 5).

Table 1. Mean, standard deviation and comparative analysis of subject's clinic and demographic characteristics from arthroplasty group and control group.

\begin{tabular}{lccc}
\hline & AG $(n=23)$ & CG $(n=23)$ & $\begin{array}{c}\text { Student's-t test } \\
p \text { value }\end{array}$ \\
\hline Age (years) & $72.0 \pm 6.50$ & $70.13 \pm 5.9$ & 0.313 \\
\hline BMl $\left(\mathrm{Kg} / \mathrm{m}^{2}\right)$ & $27.30 \pm 3.50$ & $26.93 \pm 3.69$ & 0.508 \\
\hline Years with THA & $2.61 \pm 1.27$ & NA & NA \\
\hline
\end{tabular}

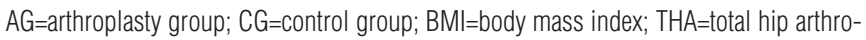
plasty; NA=not apply.

Table 2. Absolute and relative frequencies and comparative analysis of subject's clinic and demographic characteristics from arthroplasty group and control group.

\begin{tabular}{llrrrrc} 
& & \multicolumn{2}{c}{$\mathrm{AG}(\mathrm{n}=23)$} & \multicolumn{2}{c}{$\mathrm{CG}(\mathrm{n}=23)$} & Chi-Square \\
\cline { 3 - 7 } & & $\mathrm{F}$ & \multicolumn{1}{c}{$\%$} & $\mathrm{~F}$ & \multicolumn{1}{c}{$\%$} & $p$ value \\
\hline \multirow{2}{*}{ Gender } & Male & 11 & 47.8 & 11 & 47.8 & \\
\cline { 2 - 7 } & Female & 12 & 52.2 & 12 & 52.2 & 1 \\
\hline Level of & Inactive & 15 & 65.3 & 14 & 56.5 & \\
\cline { 2 - 7 } $\begin{array}{l}\text { physical } \\
\text { activity }\end{array}$ & Insufficient & 7 & 30.4 & 7 & 30.5 & 0.565 \\
\cline { 2 - 7 } & Moderate & 1 & 4.3 & 2 & 13.0 & \\
\cline { 2 - 7 } & Vigorous & 0 & 0.0 & 0 & 0.0 & \\
\hline
\end{tabular}

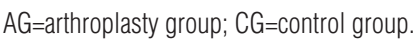

\section{Discussion $: \because$.}

This study aimed to evaluate gait parameters in distinct test situations and the functional performance of a group comprised of older adults with a mean of $2.6 \pm 1.27$ years since THA and another group of older adults without a history of THA. The results show differences between groups, with a worse performance for the AG subjects on both gait parameters and functional tests. When gait parameters were compared between the LLs of the AG subjects, the differences were statistically significant.

Analyses of gait parameters after THA have been discussed in the literature, which includes a variety of studies done in distinct postoperative periods. Some authors have assessed the gait of subjects post-arthroplasty after 11 days ${ }^{25}$, four weeks ${ }^{26}$, six months ${ }^{27}$, one year ${ }^{9}$ and ten years ${ }^{8}$, observing modification to $\mathrm{GS}^{8,25}$, step length ${ }^{9,26}$ and duration of the stance phase of the gait $^{8,27}$. The variations in the period post-THA in these studies demonstrate a lack of agreement regarding the postsurgical period in which gait pattern modifications are most evident. Data from the present research indicated a mean time of 2.6 \pm 1.7 years after THA and suggest the permanence of gait alterations. This postoperative time interval allowed for an assessment without the influence of cicatrization and also characterized a stage when subjects had already adapted to their new condition with the prosthesis. The older adults from the AG and CG reported absence of pain on the day of data collection. However, the results suggest that, although the prosthetic joint was able to receive load, the participants did not perform their functions normally.

GS is one of the most often used parameters of gait assessment, due not only to its functional relevance but also to its easy evaluation ${ }^{5,6}$. The diverse methods described in the literature to assess GS allow for gait evaluation in a form similar to typical environmental demands and daily tasks ${ }^{6}$. A study from Sicard-Rosenbaum, Light and Behrman ${ }^{28}$ identified mean values of US and FS similar to those found in the present study, both for the group with THA (US=1.1 m/s and $\mathrm{FS}=1.5 \mathrm{~m} / \mathrm{s}$ ) and for controls (US=1.30 m/s and $\mathrm{FS}=1.80$ $\mathrm{m} / \mathrm{s})$. Although the population evaluated by the authors was younger (60.2 \pm 15.0 years), the length of the postoperative period was similar to that used herein (23.6 \pm 14.8 months). Similarly, our results are consistent with those of Perron et al. ${ }^{29}$, who concluded that the GS of older adults after a period of two to four years after THA remained 15 to $25 \%$ below the values of the CG. In the present study, the observed values for the AG were lower than those for the CG, with reductions of $16 \%$ on US, $19 \%$ on FS, $14 \%$ on SS and $13 \%$ on DT. It is valuable to note that GS is related to independence on $\mathrm{ADLs}^{21}$, risk of falls ${ }^{6}$ and fear of falling ${ }^{25}$. Such findings are consistent with the 
Table 3. Mean, standard deviation and comparative analysis of gait parameters between operated limb and non operated limb of arthroplasty group in different situations.

\begin{tabular}{|c|c|c|c|c|}
\hline & & $\mathrm{OL}$ & NOL & $\begin{array}{l}\text { Paired Student's-t test } \\
\qquad p \text { value }\end{array}$ \\
\hline \multirow[t]{4}{*}{ Step length } & US & $53.50 \pm 6.99$ & $49.36 \pm 8.88$ & ${ }^{\star} 0.000$ \\
\hline & FS & $63.33 \pm 6.38$ & $60.33 \pm 6.12$ & ${ }^{*} 0.000$ \\
\hline & SS & $53.14 \pm 5.45$ & $51.11 \pm 5.41$ & ${ }^{*} 0.000$ \\
\hline & DT & $53.43 \pm 7.98$ & $50.18 \pm 8.46$ & ${ }^{*} 0.000$ \\
\hline \multirow[t]{4}{*}{ Step time } & US & $0.54 \pm 0.034$ & $0.56 \pm 0.22$ & ${ }^{\star} 0.001$ \\
\hline & FS & $0.48 \pm 0.053$ & $0.53 \pm 0.036$ & ${ }^{*} 0.000$ \\
\hline & SS & $0.57 \pm 0.090$ & $0.58 \pm 0.60$ & ${ }^{*} 0.027$ \\
\hline & DT & $0.60 \pm 0.087$ & $0.62 \pm 0.024$ & ${ }^{\star} 0.008$ \\
\hline \multirow[t]{4}{*}{ Stance phase (\%) } & US & $59.07 \pm 1.02$ & $60.31 \pm 1.05$ & ${ }^{*} 0.012$ \\
\hline & FS & $58.13 \pm 1.05$ & $60.33 \pm 6.12$ & ${ }^{\star} 0.004$ \\
\hline & SS & $60.03 \pm 1.76$ & $63.08 \pm 1.65$ & ${ }^{*} 0.001$ \\
\hline & DT & $57.72 \pm 1.01$ & $60.01 \pm 0.91$ & ${ }^{*} 0.000$ \\
\hline \multirow[t]{4}{*}{ Single support (\%) } & US & $37.47 \pm 1.25$ & $39.94 \pm 0.72$ & ${ }^{\star} 0.002$ \\
\hline & FS & $37.32 \pm 0.90$ & $41.07 \pm 1.10$ & ${ }^{\star} 0.001$ \\
\hline & SS & $37.87 \pm 1.22$ & $40.02 \pm 1.50$ & ${ }^{*} 0.002$ \\
\hline & DT & $36.10 \pm 1.17$ & $38.37 \pm 1.21$ & ${ }^{\star} 0.005$ \\
\hline
\end{tabular}

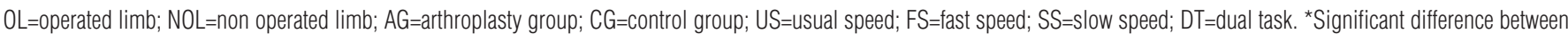
operated limb and non operated limb.

Table 4. Mean, standard deviation and comparative analysis of gait paremeters between arthroplasty group and control group in different situations and of Timed Up and Go test and Dynamic Gait Index test.

\begin{tabular}{|c|c|c|c|c|}
\hline & & $A G$ & CG & $\begin{array}{l}\text { Student's-t test } \\
\quad p \text { value }\end{array}$ \\
\hline \multirow[t]{4}{*}{ Speed } & US & $1.18 \pm 0.13$ & $1.39 \pm 0.09$ & ${ }^{*} 0.012$ \\
\hline & FS & $1.52 \pm 0.20$ & $1.86 \pm 0.13$ & ${ }^{*} 0.015$ \\
\hline & SS & $0.94 \pm 0.14$ & $1.09 \pm 0.12$ & ${ }^{*} 0.013$ \\
\hline & DT & $0.99 \pm 0.20$ & $1.14 \pm 0.13$ & ${ }^{\star} 0.003$ \\
\hline \multirow[t]{4}{*}{ Cadence } & US & $107.83 \pm 7.58$ & $105.12 \pm 7.28$ & 0.223 \\
\hline & FS & $122.43 \pm 4.78$ & $124.92 \pm 2.76$ & 0.136 \\
\hline & SS & $93.75 \pm 5.24$ & $94.29 \pm 5.09$ & 0.726 \\
\hline & DT & $98.86 \pm 3.37$ & $98.68 \pm 5.09$ & 0.888 \\
\hline \multirow{4}{*}{$\begin{array}{l}\text { Symmetry index of step } \\
\text { length }\end{array}$} & US & $3.60 \pm 1.01$ & $1.12 \pm 0.59$ & ${ }^{*} 0.000$ \\
\hline & FS & $5.80 \pm 0.87$ & $1.90 \pm 0.66$ & ${ }^{\star} 0.000$ \\
\hline & SS & $2.50 \pm 0.73$ & $1.12 \pm 0.67$ & ${ }^{*} 0.000$ \\
\hline & DT & $6.12 \pm 0.89$ & $2.77 \pm 0.77$ & ${ }^{*} 0.000$ \\
\hline \multirow[t]{4}{*}{ Symmetry index of step time } & US & $-2.65 \pm 0.92$ & $0.99 \pm 0.74$ & ${ }^{*} 0.000$ \\
\hline & FS & $-3.40 \pm 1.17$ & $1.19 \pm 0.73$ & ${ }^{*} 0.000$ \\
\hline & SS & $-3.28 \pm 1.18$ & $1.03 \pm 0.81$ & ${ }^{*} 0.000$ \\
\hline & DT & $-4.97 \pm 1.47$ & $2.55 \pm 1.10$ & ${ }^{*} 0.000$ \\
\hline \multirow{4}{*}{$\begin{array}{l}\text { Symmetry index of stance } \\
\text { phase }\end{array}$} & US & $-2.55 \pm 0.79$ & $-1.04 \pm 0.50$ & ${ }^{\star} 0.005$ \\
\hline & FS & $-3.38 \pm 0.82$ & $-2.05 \pm 0.51$ & ${ }^{*} 0.001$ \\
\hline & SS & $-1.57 \pm 0.51$ & $-1.33 \pm 0.15$ & ${ }^{*} 0.002$ \\
\hline & DT & $-2.09 \pm 0.60$ & $-0.76 \pm 0.45$ & ${ }^{*} 0.000$ \\
\hline \multirow{4}{*}{$\begin{array}{l}\text { Symmetry index of single } \\
\text { support }\end{array}$} & US & $-2.17 \pm 0.78$ & $1.21 \pm 0.51$ & ${ }^{*} 0.003$ \\
\hline & FS & $-3.24 \pm 0.71$ & $-2.08 \pm 0.77$ & ${ }^{*} 0.006$ \\
\hline & VL & $-2.53 \pm 0.70$ & $1.16 \pm 0.59$ & ${ }^{*} 0.008$ \\
\hline & DT & $-5.44 \pm 1.02$ & $2.45 \pm 1.15$ & ${ }^{\star} 0.000$ \\
\hline TUG & & $14.67 \pm 1.94$ & $10.08 \pm 1.49$ & ${ }^{*} 0.001$ \\
\hline DGI & & $20.04 \pm 1.91$ & $21.69 \pm 1.45$ & ${ }^{*} 0.001$ \\
\hline
\end{tabular}

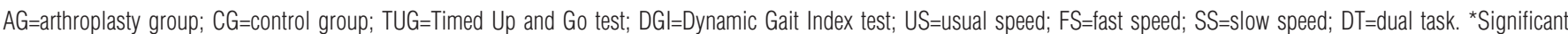
difference between arthroplasty group and control group. 
Table 5. Mean, standard deviation and comparative analysis between different situations in arthroplasty group and control group.

\begin{tabular}{|c|c|}
\hline \multicolumn{2}{|l|}{ Arthroplasty Group (AG) } \\
\hline & $\begin{array}{l}\text { Repeated measures ANOVA } \\
\qquad p \text { value }\end{array}$ \\
\hline US $(1.18 \pm 0.13) x F S(1.52 \pm 0.20)$ & ${ }^{*} 0.001$ \\
\hline US $(1.18 \pm 0.13) \times$ SS $(0.94 \pm 0.14)$ & ${ }^{*} 0.005$ \\
\hline US $(1.18 \pm 0.13)$ x DT $(0.99 \pm 0.20)$ & ${ }^{\star} 0.012$ \\
\hline FS $(1.52 \pm 0.20) \times$ SS $(0.94 \pm 0.14)$ & ${ }^{*} 0.000$ \\
\hline FS $(1.52 \pm 0.20) \times$ DT $(0.99 \pm 0.20)$ & ${ }^{\star} 0.000$ \\
\hline SS $(0.94 \pm 0.14) \times$ DT $(0.99 \pm 0.20)$ & 0.179 \\
\hline \multicolumn{2}{|l|}{ Control Group (CG) } \\
\hline US $(1.39 \pm 0.09) \times F S(1.86 \pm 0.13)$ & ${ }^{*} 0.005$ \\
\hline US $(1.39 \pm 0.09) \times S S(1.09 \pm 0.12)$ & ${ }^{*} 0.010$ \\
\hline US $(1.39 \pm 0.09) \times$ DT $(1.14 \pm 0.13)$ & ${ }^{*} 0.020$ \\
\hline FS $(1.86 \pm 0.13) \times$ SS $(1.09 \pm 0.12)$ & ${ }^{*} 0.000$ \\
\hline FS $(1.86 \pm 0.13) \times$ DT $(1.14 \pm 0.13)$ & ${ }^{\star} 0.000$ \\
\hline SS $(1.09 \pm 0.12) \times$ DT $(1.14 \pm 0.13)$ & 0.052 \\
\hline
\end{tabular}

$A G=a r t h r o p l a s t y$ group; $C G=$ control group; US=usual speed; $F S=f a s t ~ s p e e d ;$ SS=slow speed; DT=dual task. * Significant difference between different situations of gait.

present study because the AG presented worse scores on the DGI, which is an instrument capable of assessing functional capacity of subjects in situations similar to those required for the execution of ADLs. In addition, it is known that the minimum velocity necessary to cross a street safely is $1.22 \mathrm{~m} / \mathrm{s}^{30}$, and the mean values found in the present study were $1.18 \mathrm{~m} / \mathrm{s}$ for the AG and $1.39 \mathrm{~m} / \mathrm{s}$ for the CG. In this case, it is possible to deduce that the population with THA studied here had difficulties with crossing streets safely and independently.

The differences found between the diverse testing situations in both groups prove that the GS could be modified with verbal commands. The absence of difference between the situations SS and DT found in the present research supports the assumption of Hauer, Marburguer and Oester ${ }^{22}$, who affirmed that both postural control and cognitive tasks occur in the cortical level, allowing that an activity interferes with the other or causes reduction of the automatism ${ }^{22}$.

It is established that the primary determinants of GS are step length and cadence ${ }^{31}$. In the present study, although cadence behaved linearly with velocity in the distinct test situations and in both groups, there was no statistically significant difference when comparing cadence between AG and CG. In this case, it is possible to suppose that the difference in GS found between groups occurred due to differences in step length and not cadence.

In contrast, when comparing step length between the LLs of the subjects with THA, we observed a longer length for the OPL. These results are similar to those found by Bennett et al. ${ }^{5}$, who attributed this finding to the reduced capacity of the operated hip to execute the extension movement, limiting the progression of the NOL and reducing the capacity to discharge the load on the OPL. For these authors, the reduced extension of the operated hip during terminal stance led to an increase in the movements of the pelvis, knee and ankle in the sagittal plane on the same side, with a consequent threat to joint stability and an increase in energy wasted during gait ${ }^{32}$. However, the range of motion (ROM) of joints was not measured in the present study and should be studied in the future.

The step length was also shorter in the OPL when compared with the NOL, leading to a gait asymmetry, in the AG group. The step duration, measured in seconds, is defined as the interval between the initial contact of one foot and the initial contact of the other foot ${ }^{33}$. Thus the reduction in step duration may have affected the duration of stance and single support phases of gait. This relationship was observed in the results found here because the step, stance phase and single support phase durations were shorter in the OPL, and this difference was statistically significant. The reductions in stance phase and single support phase durations indicated a reduced capacity of the AG to discharge load in the OPL, despite an mean time of 2.6 years post-surgery.

McCrory, White and Lifeso ${ }^{32}$ also observed a lower load discharge on the OPL when compared with the ground reaction forces between subjects with and without a history of THA. These authors discussed that the asymmetry could be explained by the antalgic gait adopted before surgery or by alterations of strength, ROM and proprioception of the hip, suggesting that persons with joint degenerative diseases could develop adaptive gait strategies that would become routine and thus reprogram movement patterns.

The fact that the AG presented lower GS and greater asymmetry in all the analyzed gait parameters and in all test situations including SS and DT allows us to conclude that the subjects with THA presented shorter stance duration, longer step length and a smaller load discharge under the OPL in situations quite similar to those encountered daily.

Indeed, this asymmetry is associated with a worse functional status and a greater risk of fall $\mathrm{s}^{21}$ and may cause degenerative alterations of the joints of the $\mathrm{NOL}^{34}$, impairment of the integrity of the prosthesis fixation ${ }^{35}$ and a reduction in bone mineral density in the OPL ${ }^{36}$.

The mean time taken to perform the TUG was 14.67 seconds in the $\mathrm{AG}$ and 10.08 seconds in the CG. Bohannon ${ }^{37}$ indicated mean values of time reference for the TUG stratified by age. For subjects in the 70-79 year-old age group, which corresponds to the mean age of the population in the present study, the author 
determined an mean TUG time of 11.3 seconds. Considering these results, the AG's mean TUG time was higher than this value, indicating a worse functional performance as well as a difference between groups of 4.95 seconds. In a populationbased study, Thrane, Joakimsen and Thornquist ${ }^{38}$ demonstrated that the difference of 2.4 seconds in TUG performance time is clinically relevant, which suggests that the AG analyzed in the present study showed clinical-functional differences when compared with the CG, perhaps influenced by gait alterations because none of the participants reported pain on the day of data collection.

Prior to this research, studies that used the DGI to evaluate older adults with THA were not available, but it is known that scores lower than 19 points are associated with changes in gait and risk of falls ${ }^{39}$. Whitney et al. ${ }^{40}$ concluded that DGI is a good indicator of gait instability, which is associated with the risk of falls, in both old and young subjects, in addition to being appropriate for evaluating functionality of healthy older adults. However, in this research, despite the differences in the results between AG and CG, both groups presented mean DGI scores up to 19 points, suggesting the need for more research related to a cutoff point for specific populations.

There are some limitations to the present study. Although the groups were well matched on gender, age, BMI and level of physical activity, cross-sectional studies do not allow inferences of causality, preventing the conclusion that the differences between groups are caused by the THA. To reach such a conclusion, further longitudinal studies are needed in which the gait is analyzed before and after the surgical procedure. Some potentially confounding factors were minimized by the fact that all surgeries were performed by the same surgeon, with the same surgical approach and with an identical type of prosthesis. However, the fact that one-third of the AG subjects had osteoarthritis in another LL joint, even without complaints of pain on the day of data collection, may have interfered with the results, as we did not know the subject's functional status before the surgery.

\section{Conclusion $: \because$.}

Elderly subjects who had undergone THA due to osteoarthritis presented alterations in GS, step duration and length, duration of stance and single support phases, even 2.6 years post-surgery. The asymmetry was evident, with a lower load discharge on the OPL during the situations FS, SS and US associated with a cognitive task. In addition, the elderly subjects with THA had a worse functional performance on the TUG test, indicating that they did not return to normal functional status. Such findings suggest the necessity of allocating more attention to the postoperative rehabilitation of post-THA patients' gait and functional training.

\section{References : : :}

1. Mobasheri R, Gidwani S, Rosson JW. The effect of total hip replacement on the employment status of patients under the age of 60 years. Ann R Coll Surg Engl. 2006;88(2):131-3.

2. Iorio R, Robb WJ, Healy WL, Berry DJ, Hozack WJ, Kyle RF, et al. Orthopaedic surgeon workforce and volume assessment for total hip and knee replacement in the United States: preparing for an epidemic. J Bone Joint Surg Am. 2008;90(7):1598-605.

3. Jennedy DM, Stratford PW, Hanna SE, Wessel J, Gollish J. Modeling early recovery of physical function following hip and knee arthroplasty. BMC Musculoskelet Disord. 2006;7:100.

4. Nantel J, Termoz N, Vendittoli PA, Lavigne M, Prince F. Gait patterns after total hip arthroplasty and surface replacement arthroplasty. Arch Phys Med Rehabil. 2009;90(3):463-9.

5. Bennett D, Humphreys L, O'brien S, Kelly C, Orr JF, Beverland DE. Gait kinematics of agestratified hip replacement patients - A large scale, long-term follow-up study. Gait Posture. 2008;28(2):194-200

6. van den Akker-Scheek I, Stevens M, Bulstra SK, Groothoff JW, van Horn JR, Zijlstra W. Recovery of gait after short-stay total hip arthroplasty. Arch Phys Med Rehabil. 2007;88(3):361-7.

7. Maffiuletti NA, Impellizzeri FM, Widler K, Bizzini M, Kain MSH. Spatiotemporal parameters of gait after total hip replacement: anterior versus posterior approach. Orthop Clin North Am. 2009;40(3):407-15

8. Kyriasis V, Rigas C. Temporal gait analysis of the osteoarthritic patients operated with cementless hip replacement. Clin Biomech (Bristol, Avon). 2002;17(4):318-21.

9. Rasch A, Dalén N, Berg HE. Muscle strength, gait, and balance in 20 patients with hip osteoarthritis followed for 2 years after THA. Acta Orthop. 2010;81(2):183-8.

10. Youdas JW, Hollman JH, Aalbers MJ, Ahrenholz HN, Aten RA, Cremers JJ. Agreement between the GAITRite walkway system and a stopwatch-footfall count method for measurement of temporal and spatial gait parameters. Arch Phys Med Rehabil. 2006;87(12):1648-52.

11. Webster KE, Wittwer J, Feller JA. Validity of the GAITRite walkway system for the measurement of averaged and individual step parameters of gait. Gait Posture. 2005;22(4):317-21.

12. Menz HB, Latt MD, Tiedemann A, Mun San Kwan M, Lord SR. Reliability of the GAITRite $®$ walkway system for the quantification of temporo-spatial parameters of gait in young and older people. Gait Posture. 2004;20(1):20-5.

13. Brucki SMD, Nitrini R, Caramelli P, Bertolucci PF, Okamoto IH. Sugestões para o uso do miniexame do estado mental no Brasil. Arq Neuropsiquiatr. 2003;61(3B):777-81.

14. De Castro S, Perracini M, Ganança F. Dynamic Gait index - Brazilian Version. Rev Bras Otorrinolaringol. 2006;72(6):817-25

15. Shumway-Cook A, Woolacott MH. Control of posture and balance.in: motor control theory and practical. Applications.maryland: Willians \& Wilkins; 1995.

16. Marchetti GF, Withney SL, Blatt PJ, Morris LO, Vance JM. Temporal and spatial characteristics of gait during performance of the Dynamic Gait Index in people with and people without balance or vestibular disorders. Phys Ther. 2008;88(5):640-51.

17. Mathias S, Nayak US, Isaacs B. Balance in elderly patients: The "Get-up and Go" test. Arch Phys Med Rehabil. 1986;67(6):387-9.

18. Podsiadlo D, Richardson S. The timed "Up \& Go": A test of basic functional mobility for frai elderly persons. J Am Geriatr Soc. 1991;39(2):142-8.

19. Wall JC, Bell C, Campbell S, Davis J. The timed get-up-and-go test revisited: measurement of the component tasks. J Rehabil Res Dev. 2000;37(1):109-13. 
20. Daughton DM, Fix AJ, Kass I, Bell CW, Patil KD. Maximum oxygen consumption and the ADAPT quality-of-life scale. Arch Phys Med Rehabil. 1982;63(12):620-2.

21. Bloem BR, Valkenburg VV, Slabbekoorn M, Willemsen MD. The multiple tasks test: development and normal strategies. Gait Posture. 2001;14(3):191-202.

22. Hauer K, Marburguer C, Oester P. Motor performance deteriorates with simultaneously performed cognitive tasks in geriatric patients. Arch Phys Med Rehabil. 2002;83(2):217-23.

23. Megan Zachar BS. GAITRite Manual. Version 3.9 MAP/CIR INC. Havertown, PA 19083. 09/06junho/2007.

24. Galea MP, Levinger RP, Lythgo N, Cimoli C, Weller R, Tully E, et al. A target home- and centerbased exercise program for people after total hip replacement: a randomized clinical trial. Arch Phys Med Rehabil. 2008;89(8):1442-7.

25. Giaquinto S, Ciotola E, Margutti F. Gait in the early days after total knee and hip arthroplasty: a comparison. Disabil Rehabil. 2007;29(9):731-6.

26. Nankaku M, Tsuboyama T, Kakinoki R, Kawanabe K, Kanzaki H, Mito Y, et al. Gait analysis of patients in early stages after total hip arthroplasty: effect of lateral trunk displacement on walking efficiency. J Orthop Sci. 2007;12(6):550-4.

27. Madsen MS, Ritter MA, Morris HH, Meding JB, Berend ME, Faris PM, et al. The effect of total hip arthroplasty surgical approach on gait. J Orthop Res. 2004;22(1):44-50.

28. Sicard-Rosenbaum L, Light KE, Behrman AL. Gait, lower extremity strength, and self-assessed mobility after hip arthroplasty. J Gerontol A Biol Sci Med Sci. 2002;57(1):M47-51.

29. Perron M, Malouin F, Moffet $\mathrm{H}$, McFadyen BJ. Three-dimensional gait analysis in women with a total hip arthroplasty, Clin Biomech (Avon, Bristol). 2000;15(7):504-15.

30. Wang AW, Gilbey HJ, Ackland TR. Perioperative exercise programs improve early return of ambulatory function after total hip arthroplasty: A randomized, controlled trial. Am J Phys Med Rehabil. 2002;81(11):801-6.

31. Prince F, Corriveau H, Hébert R, Winter DA. Gait in the elderly. Gait Posture. 1997;5(2):128-35.

32. McCrory JL, White SC, Lifeso RM. Vertical ground reaction forces: objective measures of gait following hip arthroplasty. Gait Posture. 2001;14(2):104-9.

33. Perry J. Análise de marcha. $1^{\text {a }}$ Ed. Barueri (SP): Manole; 2005.

34. Husby VS, Helgerud J, Bjørgen S, Husby OS, Benum P, Hoff J. Early postoperative maxima strength training improves work efficiency 6-12 months after osteoarthritis induced total hip arthroplasty in patients younger than 60 years. Am J Phys Med Rehabil. 2010;89(4):304-14.

35. Nallegowda M, Singh U, Bhan S, Wadhwa S, Handa G, Dwivedi SN. Balance and gait in total hip replacement: A pilot study. Am J Phys Med Rehabil. 2003;82(9):669-77.

36. Mont MA, Seyler TM, Ragland PS, Starr R, Erhart J, Bhave A. Gait analysis of patients with resurfacing hip arthroplasty compared with hip osteoarthritis and standard total hip arthroplasty. J Arthroplasty. 2007;22(1):100-8.

37. Bohannon RW. Reference values for the timed up and go test: a descriptive meta-analysis. J Geriatr Phys Ther. 2006;29(2):64-8.

38. Thrane G, Joakimsen RM, Thornquist E. The association between timed up and go test and history of falls: The Tromso study. BMC Geriatr. 2007;7:1.

39. Wrisley DM, Marchetti GF, Kuharsky DK, Whitney SL. Reliability, internal consistency, and validity of data obtained with the functional gait assessment. Phys Ther. 2004;4(10):906-18.

40. Whitney SL, Marchetti GF, Schade A, Wrisley DM. The sensitivity and specificity of the Timed "Up \& Go" and the dynamic gait index for self-reported falls in persons with vestibular disorders. $J$ Vestib Res. 2004;14(5):397-409. 